\title{
English Learning and Cultural Recognition among Mongolian College Students - Case Studies among Mongolian English Majors in IMUN
}

\author{
$\mathrm{Ji}^{-N a n} \mathrm{Jia}^{1}$ \\ ${ }^{1}$ Foreign language school, Inner Mongolian University for Nationalities, Tongliao, Inner Mongolian, China \\ Correspondence: Ji-Nan Jia, Foreign language school, Inner Mongolian University for Nationalities, Tongliao, \\ Inner Mongolian, China. E-mail: jiajinan@imun.edu.cn
}

\author{
Received: January 22, 2014 Accepted: March 18, 2014 Online Published: May 27, 2014 \\ doi:10.5539/ells.v4n2p37 URL: http://dx.doi.org/10.5539/ells.v4n2p37
}

\begin{abstract}
Through the questionnaire and interview, this paper carries out research on the Mongolian English majors in Inner Mongolia University for the Nationalities (IMUN), and these research studies are designed to reflect their recognition of their native culture and the English culture after they started to learn English. Results indicate that Mongolian English majors in IMUN have preserved and inherited the traditions in their native culture and showed recognition of the cultural identity of their ethnic group. At the same time, some influences from the English culture have also managed to seep into their behavioral and thinking patterns gradually. They show positive attitudes towards both their native culture and the English culture in terms of language learning and cultural inheritance and protection.
\end{abstract}

Keywords: English learning, cultural recognition, Mongolian college student

\section{Introduction}

Cultural Identity is defined as the identity of a group or culture or an individual's recognition of the group or culture to which he/she belongs due to its influences (Liu, 2000). As a positive judgment of cultural value, cultural identity refers to the attitude and method with which a cultural group or members in a culture recognize the value effect of a new culture in this group or an exogenous cultural factor as conforming to the value standards of traditional culture (Ren, 2008). The recognized new culture or exogenous cultural factors will be accepted and transmitted (Fan, 2011). Different cultures or different parts within the same culture may undergo a process of contact and assimilation. Judging from assimilation type, people either show recognition of exogenous cultures or express approval for their own cultures; from the perspective of content, recognition can be divided into positive recognition and negative recognition; and from the angle of assimilation trend, it consists of progressive assimilation (interpreting exogenous cultures within the framework of the culture to which subjects belong) and regressive assimilation (analyzing and interpreting subjects' cultures within the framework of exogenous cultures) (Xie, 1999). Cultural recognition is a system composed of multi-cultural elements, including experience, belief, behavior, attitude, customs, value outlook, eating patterns, etc. In this paper, cultural recognition refers to language learners' recognition and acceptance of their native culture as well as the culture of the target language. Mongolian English Majors in IMUN are in fact a special group because of their trilingual and multicultural background. Their mother-tongue is Mongolia and they own their arts and traditional customs. Do they experience any cultural identity changes after they started to learn English? If they do, to what extent? Thus, this paper focuses on relationships between Mongolian English Majors' cultural identity and their English learning, aiming to find out their cultural identity status and whether "productive bilingualism" exists in the Mongolian English Majors in Inner Mongolia University for the Nationalities. It is hoped that this research would enrich and benefit Minority English Majors' English teaching and improve their intercultural communication competence.

\section{Literature Review}

As far as foreign language education is concerned, the cultural identity of the language learners is a complex topic that is worthy of further exploration, because it is significant for foreign language teaching and intercultural communication.

In recent years, few scholars get involved in studies on language learners' cultural recognition, but there is an 
increasing trend year by year. Many scholars at home and abroad have been carrying out researches on this topic from different perspectives (e.g., Chen, 2005; Kim, 2003; Kinginer \& Belz, 2005; Moss \& Faux, 2006; Reuter, 2006; Spencer-oatey, 2007; Liu Shuang, 2000). From the perspective of culture and identity, Wang (2004) carried out research on religious beliefs, lifestyles, and cultural identity of Chinese Indonesian students. Results of survey showed that Chinese Indonesian students preserved the traditional Chinese culture in many aspects and possessed a strong sense of identity. They retained the recognition of their identity as Chinese by identifying themselves with Chinese culture. However, they had also accepted some customs and ideas from Indonesia and the West.

In addition, Chen $(2005$, p. 63) believed that cultural identity is "awareness that belongs to a certain cultural group". She explained cultural identity on two levels: On the group level, cultural identity refers to the group members' cultural characteristics by which they are being regarded as social entities. On the individual level, cultural identity is a kind of psychological mechanisms which people gradually form and develop from childhood during the socialization process, a dynamic mechanism with continuous improvement. Moss and Faux (2006, p. 22) define cultural identity/recognition as "the behavior through which individual or group members show their belongingness to the group, the understanding of conditions required for being member of this group, and the ability to participate in social practice by means acceptable to the group members". In other words, speeches and behaviors of individual tend to reflect his belongingness to the group, and whether his speeches and behaviors are proper is often revealed in his group environment. They also held that cultural identity is not fixed but constantly created through a variety of ways, including "avowal", "ascription", "salience", and "intensity". According to Hecht et al. (2003), "avowal" refers to how individual shows his belongingness to the group via his own behaviors, while "ascription" refers to how individual shows his belongingness to the group via someone else. Communicator shows his belongingness to the group via his cultural communication objects when applying language norms of native culture during intercultural communication. Furthermore, the prominence and intensity of cultural identity supposedly vary due to the influences of communicative context. Low, Akande, and Hill (2005) also hold that cultural identity is inseparable from the specific social and cultural context since its development only proceeds in a certain social and cultural context.

Liu (2000), who explores the impact of culture on behaviors and approaches of language communication from the perspective of cultural identity, argues that "cultural identity is a cultural group member's recognition of his own cultural belongingness, with its characteristics manifesting through speeches, behaviors, ideas, and feelings of the cultural group members" (Liu, 2000, p. 87). In the light of previous studies, Liu summed up the connotations of cultural identity as seven aspects: First, self-awareness, including processes of self- and general recognitions. The self-recognition refers to a group representing the image of its own, i.e., myself (ourselves), to others. The general recognition refers to the image of a group endowed and accepted by others. Second, manifestations since cultural identity is a product of the communication process, and each culture has a system of symbols and behavioral norms as approaches to express the cultural group's faith, values, and worldviews. One kind of symbols has different meanings for different cultural groups. Third, relationship as an identity can be manifested through the situation of members' relationships. Fourth, inertia and action in that culture is inherited, generation by generation, by members of a group. Traditional behavioral norms, ethics, and values are still in use today, but cultural identity changes as society changes at the same time. Fifth, emotional factors. Cultural recognition is emotional, and people tend to generate a sense of superiority and pride for the culture of their own group. Sixth, content of information communication. Cultural identity determines how people pass the information of what topic to each other in what circumstances and explain the content of information in which kind of context. Finally, cultural identity will change with the environment, and the reflection of cultural identity awareness in group members varies in degrees of intensity (Liu, 2005).

In English Learning and Change of Self-recognition: A Quantitative Study for Undergraduates, 2003, scholar Gao Yihong carried out a research on undergraduates' change of self-recognition after they started to learn English via the questionnaire. There were 2,278 undergraduates from 30 universities across the country who were surveyed by stratified sampling. Change of self-recognition was measured with questions divided in six categories: confidence, productivity, additivity, fissility, reducing change, and zero change (the reference category). Results showed that English learning had an outstanding influence on the learners' confidence, and, meanwhile, their cultural values and communicative approaches had experienced changes in productivity and additivity to some extent. Gender, major, and age starting to learn English also had significant influences on change of self-recognition in some aspects.

In Motivation of English Learning and Change of Self-recognition Follow-up: A Sample Report on Senior English Majors in Comprehensive Universities (2012), Gao Yihong, combining quantitative and qualitative 
methods, explored the motivation of English learning and change of self-recognition in senior English majors in comprehensive universities. As a result, she found that, while sustaining the trend of the previous three years, the students' motivation and recognition had also changed. For example, intensity of motivation was obviously declined and situational motivation was somewhat increased; reducing change had rose to the highest point in four years while motivation of social responsibility and change in productivity had decreased. The qualitative materials further revealed the diversity, complexity, and tortuosity of motivation and recognition.

The seven aspects summed up by Liu (2004) made a fairly comprehensive overview of the connotation of culture identity, while Gao (2008) explained the necessity of studies on recognition of identity of foreign language learners. The drawback of these studies is that the other aspects of language learners were not involved. For instance, have the foreign language learners of ethnic minorities with multi-language and diverse educational background (such as Mongolian English majors in Inner Mongolia University for the Nationalities) established a cultural identity associated with the English language after years of foreign language learning? And if so, is there any difference between levels of recognition of their native cultural identity and English cultural identity? Moreover, will the differences of their English proficiency influence their cultural identity? We assume that foreign language learners may develop a new kind of cultural identity, i.e., foreign/target language cultural identity, while maintaining the native cultural identity. And this identity will change due to the development of foreign language proficiency.

\section{Research Background, Objective, and Methods}

\subsection{Research Background and Questions}

Mongolian English majors in IMUN constitute a special English-learning group. They possess rich Mongolian cultural connotations and have their own writing system, religion as well as unique culture, art, and customs.

Based on the data collected from the questionnaire and interview, this paper carries out a manifold and multi-dimensional study on subjects' religion, cultural conventions, festivals, language learning, and cultural inheritance. It is designed to investigate whether influences from multiple exogenous cultures have made a difference in subjects' recognition and inheritance of their own culture and whether there is any change in their recognition of their native culture. Besides, this study is also designed to find out whether the subjects show any recognition of the English culture. If they do, to what extent?

\subsection{Design}

The writer conducts research studies on 110 Mongolian English majors from Grade 2012 to Grade 2009 in IMUN. During the research, the questionnaire is taken as the major method while the interview and observation are taken as supplements. Also, both quantitative methods and qualitative ones are employed in this study. For questionnaire data, EXCEL is adopted to do quantitative analysis while descriptive analysis is used for interview and observation. By doing so, the study material can be analyzed and interpreted in a more scientific way.

\subsubsection{Subjects}

Subjects of this study include 110 Mongolian English majors. Altogether, 120 questionnaires are distributed and 117 pieces collected with 110 valid questionnaires. Among them, 4 subjects are boys, accounting for $3 \%$, and 106 are girls, making up 96\%. In addition, their age ranges from 19 to 24, and16 of them have passed CET-4 (College English Test-Band 4).

\subsubsection{Research Tools}

Based on the items in the cultural identity part of Gao Yihong's (2008) questionnaire on self-recognition, this questionnaire integrates subjects' specific conditions and takes into consideration the different aspects of culture, including religious belief, culture and art, language learning, and daily life, etc. This questionnaire altogether includes 4 parts - subjects' information, questionnaire of native culture recognition, questionnaire of English culture recognition, and questionnaire of cultural recognition changes. Among them, questionnaire of cultural recognition changes will be discussed in details in future articles. The first part covers subjects' basic information, including name, gender, age, and time-span of English learning; the second part includes the questionnaire of native culture recognition and is designed to survey learners' recognition of their native culture; and the third part is the questionnaire of English culture recognition and is designed to survey learners' recognition of the target culture. One noticeable thing is that items in part two and part three correspond to each other. Each of them are classified into 9 categories including 18 items: learners' attitudes and recognition of religious belief (items 2 and 3), learners' attitudes and recognition of language learning (items 16-18), learners' attitudes and recognition of festivals (items 4 and 5), learners' attitudes and recognition of culture and art including poetry, songs, and dance (items 6-8), their choices of daily life including eating habits and clothing 
(items 1 and 9), marriage concept (item 8), customs and taboos (items 10-13), cultural recognition (items 14 and 15), and language learning (items 16-18). The Cronbach's alpha of this questionnaire is 0.617. Based on the problems that occur in prediction and the suggestions from subjects, we revise the questionnaire. So, the Cronbach's alpha of the formal questionnaire is 0.78 . This questionnaire is designed based on the Likert Scale, and every item in it has 5 scales, including "Strongly agree", "Agree", "Not sure", "Disagree", and "Strongly disagree", which will be scaled as 1,2,3,4, and 5 respectively. This is designed to reflect the strength of subjects' attitudes or their attitude differences on this scale.

\section{Results and Discussion}

\subsection{Results}

Table 1. Distribution of subjects' answers to test their recognition of native culture

\begin{tabular}{ccccccccc}
\hline & Food & Religion & Festivals & Marriage & Clothing & Custom & Language & Culture \\
\hline $\begin{array}{c}\text { Strongly } \\
\text { agree or } \\
\text { Agree }\end{array}$ & $89 \%$ & $85 \%$ & $87.3 \%$ & $87.4 \%$ & $32 \%$ & $82.3 \%$ & $91.3 \%$ & $93.5 \%$ \\
\hline
\end{tabular}

Table 2. Distribution of subjects' answers to test their recognition of English culture

\begin{tabular}{ccccccccc}
\hline & Food & Religion & Festivals & Marriage & Clothing & Custom & Language & Culture \\
\hline $\begin{array}{c}\text { Strongly } \\
\text { agree or } \\
\text { Agree }\end{array}$ & $44.6 \%$ & $0 \%$ & $45.8 \%$ & $11.8 \%$ & $71.8 \%$ & $20.3 \%$ & $82.8 \%$ & $88.4 \%$ \\
\hline Not sure & $31.3 \%$ & $4 \%$ & $23.1 \%$ & $12.9 \%$ & $12.9 \%$ & $37.3 \%$ & $13.6 \%$ & $22 \%$ \\
\hline $\begin{array}{c}\text { Disagree or } \\
\begin{array}{c}\text { Strongly } \\
\text { disagree }\end{array}\end{array}$ & $24.1 \%$ & $96 \%$ & $31.1 \%$ & $75.3 \%$ & $15.3 \%$ & $41.8 \%$ & $13.6 \%$ & $14.4 \%$ \\
\hline
\end{tabular}

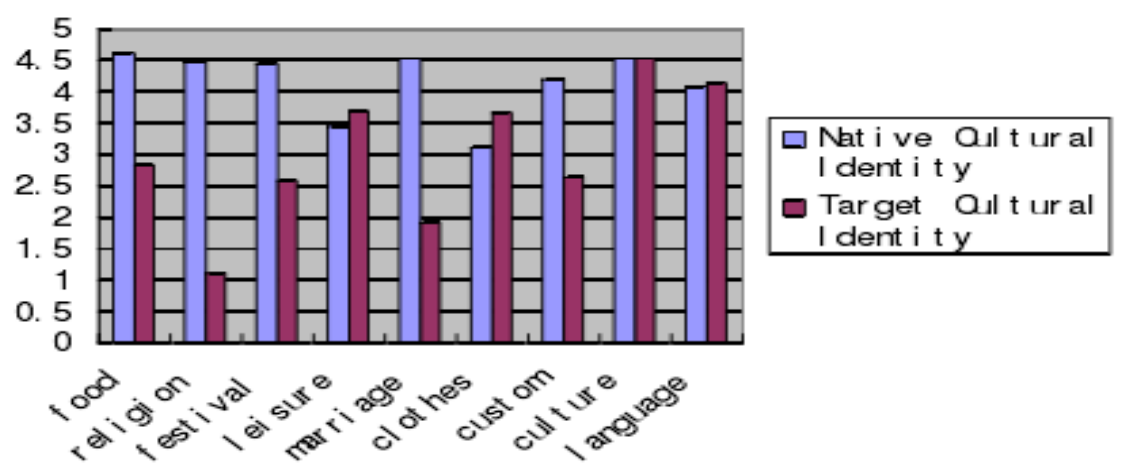

Figure 1. Recognition of native culture and English culture Histogram

Tables 1 and 2 compare subjects' answers in every questions in the questionnaire designed to test their recognition of their native culture and the English culture whose results are clearly shown and compared in Figure 1. Data show that most subjects recognize their native culture to a large extent. From their mental processes, they preserve their own religious belief, life rituals, and festival customs to maintain their recognition of their native culture; from an external perspective, in addition to their ethnic culture, they have also accepted some norms in the English culture. At the same time, after learning English for many years, they have a good understanding of the English culture which, in turn, exerts some influences on them. For example, they display some changes or even show positive attitudes in their recognition of the English culture with religion excluded. In terms of some behavioral and thinking patterns, subjects show similar recognition of their native culture and the English culture. Especially when it comes to the attitudes towards language learning and cultural inheritance 
and preservation, subjects display high recognition of their native culture. But for clothing, music, film, and art, they show a preference for those in the English culture. In addition, they are more tolerant and inclusive in the preservation of word languages and cultural diversity. In fact, preserving their own culture doesn't go against accepting advanced elements in other cultures. In essence, these subjects are undergoing a process of acquisition rather than losing their native culture, and this indicates that two cultures can get along with each other (Gao, 2005). In conclusion, subjects show better recognition of the English culture in terms of language learning, cultural preservation and inheritance, art and clothing but different subjects display different preference degrees.

\subsection{Discussion}

\subsubsection{Religious Belief and Folk Culture}

Subjects neither practice Catholicism or Christianity nor know much about the religions in English-speaking countries. They only know the existence of Catholicism and Christianity but do not have a good knowledge of their origins, development, or doctrines. This is greatly related to their motives in learning English. Different from ESL environment, English learning and teaching in China are rooted in an EFL environment where English is mostly taught as a powerful tool.

From the above analysis, it can be noticed that subjects preserve their native cultural identity by practicing their religion and upholding the folk beliefs and traditions of their ethnic group. In religious belief and folk culture, Mongolian English majors have strong recognition and sense of belonging for their native cultural identities.

\subsubsection{Dietary Habits}

Cultural identity is composed of many cultural elements, and dietary habit constitutes one of the commonest. In fact, dietary habit is the surface representation of cultural types and the best point to observe a culture as it has specific and obvious cultural features. Every nation and every religion have their own demands and taboos on their diets. This is true of ethnic minorities. They have their eating and drinking rules and have developed unique catering cultures. Therefore, it is indispensable to survey dietary habits if we want to study the status quo of cultural recognition among English majors of ethnic minorities. In the questionnaire, the writer has investigated subjects' preference degree towards foods of their ethnic group and the West. Results indicate that in terms of dietary opinions and rules and eating customs, $87 \%$ subjects say they prefer their traditional diet. Judging from this, it can be seen that English majors from ethnic minorities are quite accustomed to their native diet due to the influences from family and religion. Like teenagers in many other countries and places, they are also affected by western cultures and have come to accept western food. Among these subjects, $44.6 \%$ say that they like western food. Their fondness of diets from different cultures reflects that the diet culture of Mongolian English majors is a combination of their own culture, the Chinese culture, and the western culture.

\subsubsection{Clothing}

The clothing of an ethnic group is the treasure of its civilization as well as the external representation of its ethnic spirits. For a nation or an ethnic group, clothing reflects its humanistic spirits, aesthetic tastes, and customs as well as its psychology, temperament, and characters. Besides, clothing can also express a sense of recognition towards a nation, an ethnic group or a culture. Thirty three percent subjects express that they and their families often wear their traditional clothes while $71.8 \%$ respondents admit that they do not do that frequently. In fact, according to the interview and the author's lasting observation, ethnic groups' traditional clothes are not the mainstream in their lives any longer, and people only wear these clothes on rare occasions such as traditional festivals and wedding. The reform and opening-up and the development of commodity economy have greatly changed the lifestyles of Chinese people. In addition, clothing of ethnic people is usually featured with abundant materials, complex decorations, intricate processes, and effort-consuming manufacturing operations. These lead to lots of difficulties in wearing and washing ethnic clothing. All these factors above as well as globalization have contributed to subjects' preference for modern clothes.

\subsubsection{Festivals and Festival-Related Traditions}

Festivals and festival-related traditions constitute another important component of culture. In the interview, a survey on western festivals is carried out. For a list of major western festivals including Christmas, Easter, Thanksgiving, Valentine's Day, Halloween, Father's Day, and Mother's Day, subjects are required to choose from A "DON'T KNOW", B "KNOW", and C "CELEBRATE IT" as their answers and then provide a brief description of how they celebrate these festivals. Results show that Mongolian English majors still uphold their traditional festivals and festival-related traditions. About $88.3 \%$ respondents are very familiar with the origins and traditions of their traditional festivals and $100 \%$ of them follow the customs of these traditional festivals and celebrate them grandly. In contrast, $45.8 \%$ subjects say that they would observe some western festivals. For 
example, $60 \%$ subjects celebrate Christmas and Valentine's Day. About 50\% celebrate April Fool's Day, 45\% celebrate Father's Day and Mother's Day, but only 10\% have tried Halloween. During the interview, they all express that although they observe some western festivals, they do not do it as grandly as they celebrate their traditional ones. On Father's Day and Mother's Day, they just send their parents some small presents and on April Fool's Day they just do some pranks. When asked whether they have a good knowledge of western festivals and relevant customs, the subjects show different understanding degrees. Many western festivals are related to religions, but our subjects do not know much about western religions. This may be caused by teachers' scarcity of time to include western culture into their lectures and subjects' learning motive of taking English as a tool.

\subsubsection{Language Learning and Cultural Inheritance}

In terms of language learning and cultural inheritance, $61.3 \%$ subjects express that they like and feel fain to learn their ethnic songs, dances, and poems while $91.4 \%$ of them think their native language is beautiful and is willing to learn. Around $93.6 \%$ subjects think it is very important to protect and inherit their ethnic culture and say that they would make their own contributions to achieve this goal. Similarly, $66.2 \%$ subjects like western songs, dances, music, and poems and $82.8 \%$ subjects think English is a beautiful language and enjoy learning English. Besides, $88.4 \%$ respondents hold it quite important to learn and respect western culture. In terms of language learning, cultural inheritance and protection, literature and art, and clothes, subjects show similar attitudes towards their native culture and the English culture. This indicates that after learning English for many years, subjects have acquired an approving attitude towards English and its culture and can view linguistic and cultural diversities across the world more tolerantly.

\section{Conclusion}

The above analysis shows that Mongolian English majors inherit and preserve their ethnic cultural traditions by keeping Mongolian religion, customs, life rituals, and festivals at different degrees. They do this to maintain their recognition of their native culture and to keep their native cultural identity. At the same time, after learning English for many years, they have a good understanding of the English culture which, in turn, exerts some influences on them. For example, they display some changes or even show positive attitudes towards the English culture. This shares some similarities with the "addictive bilingualism" proposed by Lambert (1974) (Gao et al., 2003, pp. 132-139) and "productive bilingualism" proposed by Gao (2003). Besides, this also provides support for the research results of Ren (2008), Hu, Yang et al.

At present, little literature is devoted to study English learners of minority nationalities. Therefore, this study is designed to delve into the cultural recognition of English majors of minority nationalities in a detailed and in-depth way.

The modernization of any ethnic group in the world is based on the development of its traditional culture, and any culture is rich in many favorable factors that can be learned and taken as references. In teaching, instructors should encourage their students to embrace multi-cultures with a more tolerant attitude when inheriting and preserving their native cultures. This would definitely have a positive influence on the diversity of world culture.

\section{Acknowledgements}

This paper is a staged achievement of "Research of the relationship between national identity and foreign language learning motivation among Mongolian students in higher education institutions for the nationalities"- a project in the 12th "Five-Year Plan" for higher education and scientific study in Inner Mongolia Autonomous Region. (License number: NGJGH2013076)

\section{References}

Bian, Y. W. (2003). A tentative analysis of the self-recognition of foreign/second language learners. Journal of Tianjin Foreign Studies University, 78(10), 27-34.

Chen, Y. (2005). The Study of Language Use and Social Psychology. Xiamen: Xiamen University Press

Fan, Z. Y., \& Feng, T. Y. (2001). Dictionary of Chinese culture. Wuchang: Wuhan University Press.

Gao, Y. H. (2004). Social psychology of the English learning of China's college students -A study on learning motivation and self-recognition. Beijing: Foreign Language Teaching and Research Press.

Lambert, W. E. (1967). A social psychology of bilingualism. Journal of Social Issues, 89(23), 91-109. http://dx.doi.org/10.1111/j.1540-4560.1967.tb00578.x

Li, Z. Z. (2005). Identity theory and applied linguistics study. Foreign Language and Literature, 56(4), 234-242. 
Liu, S. (2000). Cultural identity and cross-cultural communication. Foreign Language Research, 126(1), 99-113.

Ren, Y. X. (2008). Research and analysis of the cultural identity among college English learners in China. Foreign Language and Literature, 16(1), 46-52.

Wang, A. P. (2000). Cultural recognition and motivation of learning Chinese among Chinese ethnic students in Southeast Asia. Journal of Huaqiao University, 66(3), 142-150.

Wang, A. P. (2004). Culture and recognition: Research of Indonesian teenagers of Chinese minority. Journal of China Renmin University, 14(6), 79-85.

Xie, X. G. (1999). Dictionary of long-distance open education. Beijing: Central Radio and TV University Press.

Yang, X. Q. (2008). Study on the relationship between foreign language learners' self-recognition and academic performance. New West, 98(20), 61.

\section{Copyrights}

Copyright for this article is retained by the author(s), with first publication rights granted to the journal.

This is an open-access article distributed under the terms and conditions of the Creative Commons Attribution license (http://creativecommons.org/licenses/by/3.0/). 